УДК 676.054.1

\title{
О ПРИМЕНЕНИИ АППАРАТА ПРОФИЛИРОВАННОЙ ФОРМЫ С РОТОРОМ ГЕЛИКОИДАЛЬНОГО ТИПА ДЛЯ ПОЛУЧЕНИЯ САНИТАРНО-ГИГИЕНИЧЕСКОЙ БУМАГИ
}

\author{
() Д.А. Иванов", К.А. Иванов, А.П. Руденко, Ю.Д. Алашкевич \\ Сибирский государственный технологический университет, пр. Мира, 82, \\ Красноярск, 660049 (Россия), e-mail: ivanov.sibstu@yandex.ru
}

\begin{abstract}
В работе приведены результаты исследований практического применения перемешивающего аппарата профилированной формы с ротором геликоидального типа на основе определения физико-механических и гидрофильных свойств санитарно-гигиенической бумаги, обеспечивающих эксплуатационные качества санитарно-гигиенических изделий.

Полученные результаты исследований показали, что применение перемешивающего аппарата профилированной формы с ротором геликоидального типа для подготовки композиции бумажной массы обеспечивает создание определенной гидродинамической обстановки в рабочей полости аппарата, позволяющей до минимума снизить возможность появления застойных зон как статического, так и динамического типа и уменьшить гидравлические потери вдоль траектории движения потока жидкости. Это, в свою очередь, ведет к максимальному увеличению степени циркуляции и равномерному распределению концентрации волокнистой суспензии для подготовки композиции бумажной массы, обеспечивающей получение требуемых физико-механических и гидрофильных свойств бумаги санитарногигиенического назначения при сравнительно низких затратах удельной электроэнергии.

Ключевые слова: аппарат профилированной формы, капиллярная впитываемость, разрушающее усилие, ротор, санитарно-гигиеническая бумага.

Работа выполнена при финансовой поддержке в рамках государственного задания по теме «Закономерности прочессов и совершенствование оборудования при заготовке древесины, глубокой химической переработке биомассы дерева и восстановлении лесов Сибири». Государственная регистраџия НИР: 01201267254.
\end{abstract}

\section{Введение}

Производство санитарно-гигиенической бумаги (СГБ) - одна из наиболее успешных отраслей мировой целлюлозно-бумажной промышленности, с каждым годом увеличивающая свои объемы производства. Общий выпуск санитарно-гигиенических изделий в мире в 2013 г. составил более 33,5 млн т [1].

Одновременно с ростом объемов производства санитарно-гигиенических изделий стремительно увеличивается конкуренция на международных и региональных рынках, что, в свою очередь, заставляет производителей санитарно-гигиенических изделий (СГИ) больше внимания уделять вопросам повышения ка-

Иванов Дмитрий Александрович - аспирант,

e-mail: ivanov.sibstu@yandex.ru

Иванов Кирилл Александрович - аспирант,

e-mail: www.kir_ill@list.ru

Руденко Анатолий Павлович - заведующий кафедрой технологии конструкционных материалов

и машиностроения, доктор технических наук, профессор, e-mail: tolyrudenko@yandex.ru

Алашкевич Юрий Давыдович - заведующий кафедрой машин и аппаратов промышленных технологий, доктор технических наук, професcop, e-mail: mapt@sibstu.kts.ru чества выпускаемой продукции, а также сокращению производственных и иных издержек (в настоящее время удельные затраты электроэнергии на осуществление процесса перемешивания бумажной массы составляют до 0,8 кВт/м ${ }^{3}$ ). Одним из путей решения поставленных вопросов является совершенствование операции перемешивания волокнистых суспензий при подготовке композиции бумажной массы.

\footnotetext{
* Автор, с которым следует вести переписку.
} 
В настоящий момент применяемые в целлюлозно-бумажной промышленности перемешивающие аппараты характеризуются несоответствием конструктивного исполнения аппарата и выполняемого процесса перемешивания, что приводит к появлению слабо перемешиваемых застойных зон в проточной полости аппарата и неустойчивости протекания самого процесса. По этой причине такие аппараты характеризуются относительно невысокой удельной производительностью процессов перемешивания и низким качеством получаемого целевого продукта. В них не удается достичь равномерного распределения подводимой энергии, что приводит к повышенным энергозатратам при эксплуатации и, следовательно, к повышению себестоимости продукции [2]. По этой причине актуальным направлением научно-технических исследований является разработка принципиально новых конструкций перемешивающих аппаратов, позволяющих существенно снизить энергозатраты при получении санитарно-гигиенической бумаги-основы.

Наличие данного обстоятельства порождает, как показали исследования, ранее проведенные авторами [3-5], реальную возможность использования перемешивающего аппарата с профилированными элементами корпуса в целлюлозно-бумажной промышленности для конструктивного исполнения функционального технологического оборудования, обеспечивающего подготовку композиции бумажной массы. В данных условиях это обеспечит как сравнительно оптимальное перемешивание (характеризующееся минимизацией количества и объема застойных зон) бумажной массы, химических компонентов путем поддержания волокон и ингредиентов во взвешенном состоянии для обеспечения выравнивания концентрации массы и придания однородности композиции во всем объеме перемешивающего аппарата перед напуском массы на сеточный стол, так и возможность более интенсивного смешивания волокнистых компонентов между собой и с химикатами, что позволяет в конечном счете снизить удельные затраты электроэнергии.

\section{Экспериментальная часть}

Определение эффективности применения разработанного перемешивающего аппарата осуществлялась на примере исследования процесса перемешивания при подготовке композиции бумажной массы, с учетом определения минимально требуемых значений физико-механических и гидрофильных свойств санитарногигиенической бумаги, обеспечивающих эксплуатационные качества санитарно-гигиенических изделий [6]. Определение физико-механических и гидрофильных свойств санитарно-гигиенической бумаги проводилось на образцах бумажных отливок, полученных после перемешивания композиции бумажной массы в аппарате профилированной формы с ротором геликоидального типа (РГТ) и верхней направляющей вставкой. Состав бумажной композиции соответствует технологическому режиму, применяемому для производства санитарногигиенической бумаги-основы на Сясьском ЦБК $[7,8]$. Бумажная масса состоит из: $60 \%$ хвойной беленой сульфитной целлюлозы (степень помола $25^{\circ}$ ШР), 40\% лиственной беленой сульфатной целлюлозы (степень помола $27^{\circ}$ ШР). Масса полученных отливок составляла $(17 \pm 1)$ г на $1 \mathrm{~m}^{2}$. Перемешивание композиции осуществлялось при концентрациях массы 0,1, 0,3 и 0,5\%. Частота вращения ротора варьировалась от 100 до 500 об/мин с шагом 100 об/мин. Время перемешивания составляло от 10 до 30 мин.

Значение концентрации суспензии оказывает влияние на однородность бумажного полотна и его физико-механические свойства. Важную роль при этом играет степень помола: для достижения необходимой прочности бумаги, обеспечивающей требуемые эксплуатационные свойства, бумажную массу из целлюлозных волокон хвойной и лиственной древесины подвергают незначительному размолу до степени помола от 23 до $25^{\circ}$ ШР [9]. Садкая бумажная масса, легко отдающая воду, при выработке тонких видов бумаги с равномерной структурой требует большего разбавления, чем при производстве более толстых видов бумаг.

Полученные результаты сравнивались с данными ТУ 5437-029-43508418-2011 «Бумага - основа для изделий бытового и санитарно-гигиенического назначения» [10].

Разрушающее усилие. По итогам проведенных исследований после перемешивания композиции бумажной массы в аппарате профилированной формы с ротором геликоидального типа были получены следующие экспериментальные данные по физико-механическим свойствам СГИ (рис. 1).

Кроме того, на основе дисперсионного анализа получено аналитическое выражение (1).

$$
P=-0,0033+0,251 \cdot c^{2}-0,0009 \cdot c \cdot n+2,5 \cdot 10^{-6} \cdot \tau \cdot n+9,21 \cdot 10^{-7} \cdot n^{2}
$$

где $\mathrm{n}$ - частота вращения перемешивающего устройства, об/мин; с - концентрация волокнистой массы, \%. 


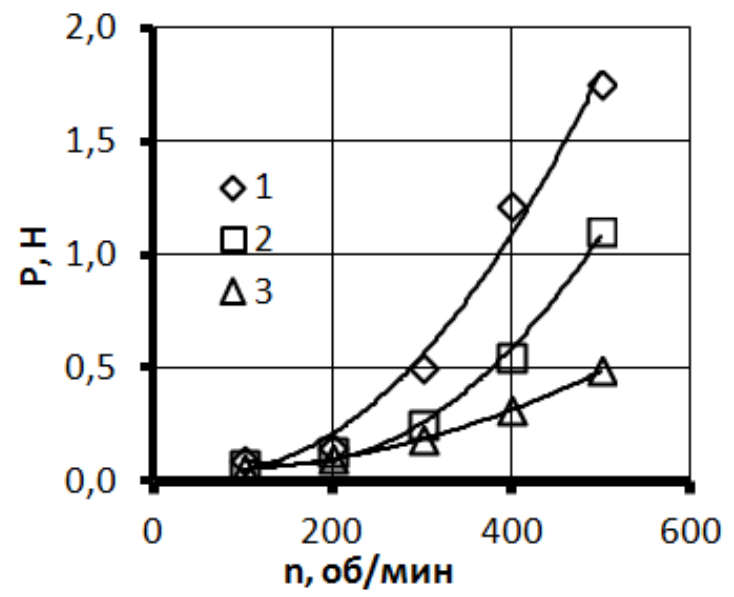

a)

Рис. 1. Графическая зависимость величины разрушающего усилия бумажных отливок от технологических режимов работы перемешивающего аппарата профилированной формы. Время перемешивания: а) $\tau=10$ мин; б) $\tau=20$ мин; в) $\tau=30$ мин. Точки $1,2,3-$ концентрация композиции волокнистой массы: $1-0,1 \% ; 2-0,3 \% ; 3-0,5 \%$

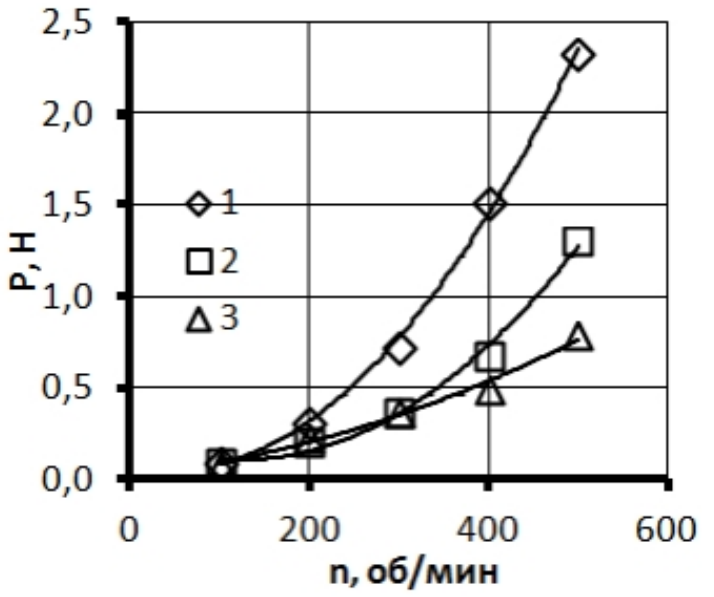

б)

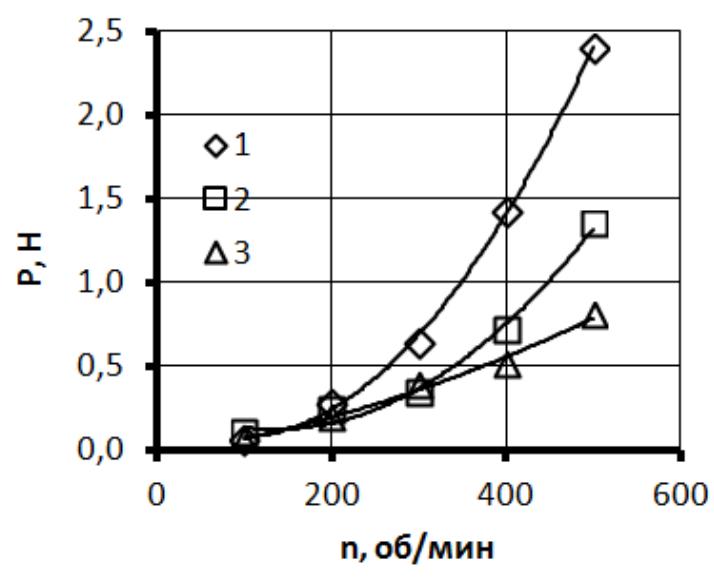

B)

Анализ графиков показал, что на свойства полученных бумажных отливок основное влияние оказывают технологические факторы: концентрация волокнистой суспензии, время перемешивания, частота вращения ротора. Так, достаточная механическая прочность бумаги (P $\geq 1,4 \mathrm{H})$ обеспечивается в результате перемешивания композиции с низкой концентрацией массы (с $=0,1 \%)$, начиная с частоты вращения ротора $\mathrm{n} \geq 400$ об/мин. При этом минимально необходимое время для перемешивания составляет около 20 мин.

Капиллярная впитываемость. Для капиллярной впитываемости, так же как и при разрывном усилии, по полученным экспериментальным данным построена графическая зависимость величины капиллярной впитываемости бумажных отливок от технологических режимов работы перемешивающего аппарата профилированной формы с ротором геликоидального типа (рис. 2) и получено аналитическое выражение (2).

На основе дисперсионного анализа получено аналитическое выражение (2):

$$
B=3,677-0,045 \cdot c \cdot n+0,0006 \cdot \tau \cdot n+0,00009 \cdot n^{2},
$$

Из представленных графиков видно (рис. 2), что капиллярная впитываемость бумаги заметно улучшается при перемешивании композиции бумажной массы низкой концентрации с $=0,1 \%$ и n $>300$ об/мин. Наиболее быстрое достижение требуемой впитываемости (В $\geq 20$ мм) наблюдается у волокнистой массы концентрацией $\mathrm{c}=0,1 \%$ с временем перемешивания массы $\tau \geq 10$ мин и частотой вращения ротора $\mathrm{n}=480$ об/мин (рис. 2а).

Из полученных результатов экспериментальных исследований следует, что процесс перемешивания в предлагаемом аппарате, обеспечивающий получение требуемых значений разрушающего усилия $(\mathrm{P} \geq 1,4 \mathrm{H})$ и капиллярной впитываемости ( $\mathrm{B} \geq 20$ мм) санитарно-гигиенической бумаги-основы, согласно ТУ 5437 029-43508418-2011, необходимо проводить по технологическому режиму, полученному для разрушающего усилия, который составляет: c $=0,1 \%, \mathrm{n} \geq 400$ об/мин, время для перемешивания композиционной массы около 20 мин. В этом случае при достижении необходимых значений разрушающего усилия автоматически будет выполняться условие получения требуемой величины капиллярной впитываемости. 


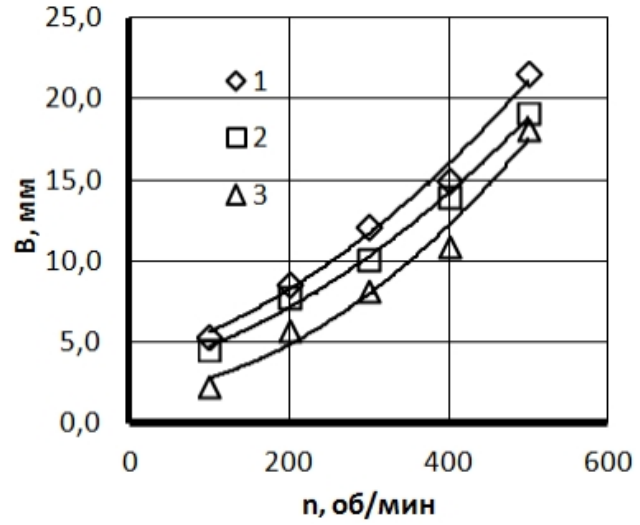

a)

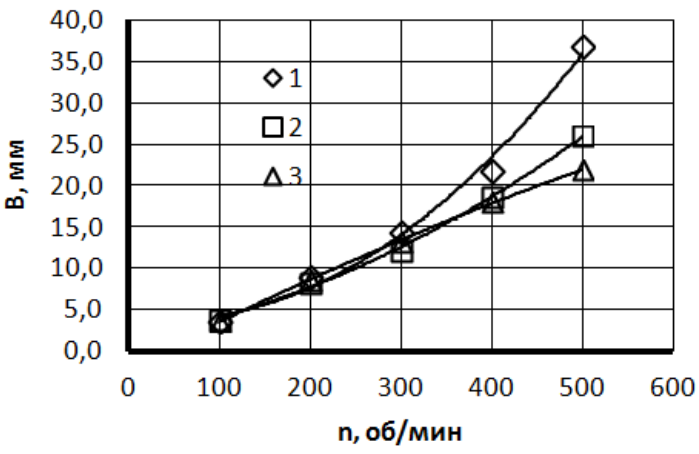

в)

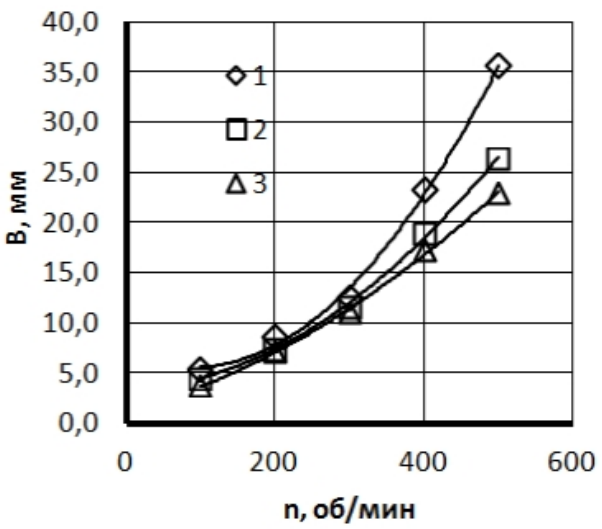

б)

Рис. 2. Графическая зависимость величины капиллярной впитываемости бумажных отливок от технологических режимов работы аппарата профилированной формы. Время перемешивания: а) $\tau=10$ мин; б) $\tau=20$ мин; в) $\tau=30$ мин. Точки 1 , 2, 3 - концентрация композиции волокнистой массы: $1-0,1 \% ; 2-0,3 \% ; 3-0,5 \%$

Затрачиваемая мощность. Мощность, затрачиваемая при работе аппарата профилированной формы, определялась по критериальному выражению $[11,12]$

$$
N=K_{N} \rho n^{3} D^{5},
$$

где $K_{N}$ - критерий мощности; $\rho$ - плотность жидкости, кг $\mathrm{M}^{3} ; n-$ частота вращения мешалки, $\mathrm{c}^{-1} ; D-$ наибольший диаметр расположения выходных кромок лопастей мешалки, м.

С использованием данной формулы, был определен критерий мощности $K_{N}$ в аппарате профилированной формы различного исполнения. Основные результаты расчета критерия мощности $K_{N}$ в аппаратах различной конструкции представлены в таблице.

Из представленных данных следует, что применение аппарата профилированной формы с установленным РГТ-270 и верхней направляющей вставкой с углом установки направляющих планок $0^{\circ}$ позволяет практически в 2 раза снизить удельные затраты электроэнергии при работе аппарата.

\section{Обсуждение результатов}

Улучшение механической прочности и впитывающей способности бумаги объясняется тем, что начиная с 300 об/мин при перемешивании массы появляются турбулентные вихри, разрушающие флоккулы. При дальнейшем увеличении частоты вращения ротора возникает устойчивый диспергированный режим движения волокнистой суспензии. В этом случае имеет место выравнивание концентрации композиционной волокнистой массы, состоящей из сульфитной хвойной и сульфатной лиственной целлюлоз. В волокнистой массе исходные волокна более равномерно распределяются между собой, а также, что имеет существенное значение, и по всему рабочему объему аппарата, обеспечивая требуемую однородность структуры бумаги при последующем отливе на сеточном столе.

Таким образом, применение перемешивающего аппарата профилированной формы с РГТ для подготовки композиции бумажной массы обеспечивает более полное проявление специфических свойств волокнистых полуфабрикатов. Так, хвойные волокна за счет содержания в них гемицеллюлозы, значительно облегчающей диспергирование при подготовке композиции бумажной массы и способствующей формированию межволоконных связей, повышают прочность бумажного листа. В свою очередь, высокое содержание пентозанов в целлюлозе лиственных пород способствует быстрой разработке последней при размоле, повышая мягкость и впитываемость производимой санитарно-гигиенической бумаги [13]. 
Значения критерия мощности $K_{N}$ в аппаратах различной конструкции

\begin{tabular}{l|c}
\hline \multicolumn{1}{c|}{ Наименование конструкции аппарата } & Критерий мощности $K_{N}$ \\
\hline Цилиндрический аппарат с турбинной мешалкой & 8,4 \\
Цилиндрический аппарат с РГТ-270 & 4,0 \\
Аппарат профилированной формы с РГТ-270 & 3,4 \\
Аппарат профилированной формы с РГТ-270 и верхней направляющей вставкой с углом \\
установки направляющих планок 0**
\end{tabular}

*Аппарат, на котором проводились исследования.

\section{Вывод}

На основании проведенных исследований и полученных результатов следует, что применение перемешивающего аппарата профилированной формы с верхней направляющей вставкой и РГТ для подготовки композиции бумажной массы обеспечивает минимальную возможность появления застойных зон как статического, так и динамического типа и уменьшение гидравлических потерь вдоль траектории движения потока жидкости. Это, в свою очередь, ведет к максимальному увеличению степени циркуляции, обеспечивающей равномерное распределение концентрации волокнистой суспензии различного композиционного состава по всему ее объему в проточной полости перемешивающего аппарата и снижению удельных затрат электроэнергии при сохранении требуемого качества получаемого продукта.

\section{Список литературы}

1. Бондаренко А. По прогнозам экспертов // Целлюлоза. Бумага. Картон. 2011. №7. С. 22-24.

2. Руденко А.П., Еременко В.В. Теоретические основы профилирования основных функциональных элементов аппарата емкостного типа // Деп. в ВИНИТИ 12.05.03, №900-В2003. 2003. 16 с.

3. Иванов Д.А., Иванов К.А., Руденко А.П. Профилирование основных элементов корпуса емкостного аппарата для обеспечения минимальных энергозатрат при эксплуатации // Молодые ученые в решении актуальных проблем науки: сб. ст. Всерос. науч.-практ. конф. Красноярск, 2010. Т. II. С. 76-78.

4. Иванов Д.А., Иванов К.А., Руденко А.П. Об основных принципах построения конструктивных элементов емкостного аппарата профилированного сечения // Наука и современность - 2011: сб. материалов IX Междунар. науч.-практ. конф. Новосибирск, 2011. Ч. 2. С. 29-32.

5. Иванов Д.А., Иванов К.А., Руденко А.П. Об эффективности применения аппарата профилированной формы с ротором геликоидального типа в ЦБП // Химия растительного сырья. 2013. №4. С. 237-242.

6. ГОСТ Р 52354-2005. Изделия из бумаги бытового и санитарно-гигиенического назначения. Общие технические условия. М., 2005. 15 с.

7. ТР №024-43508418-2008. Бумага - основа для изделий бытового и санитарно-гигиенического назначения. ОАО Сясьский целлюлозно-бумажный комбинат, 2008. 41 с.

8. ТР №006-43508418-2010. Бумага - основа для изделий бытового и санитарно-гигиенического назначения. ОАО Сясьский целлюлозно-бумажный комбинат, 2010. 43 с.

9. Смолин А.С. Основы технологии санитарно-гигиенических видов бумаги // Современные технологии и оборудование в производстве санитарно-гигиенических материалов и изделий : сб. тр. Междунар. научн.-практ. конф. СПб., 2011. С. 60-61.

10. ТУ 5437-029-43508418-2011. Бумага - основа для изделий бытового и санитарно-гигиенического назначения. ОАО Сясьский целлюлозно-бумажный комбинат, 2011. 10 с.

11. Васильцов 3.А., Ушаков В.Г. Аппараты для перемешивания жидких сред. Л., 1989. 271 с.

12. Касаткин А.Г. Основные процессы и аппараты химической технологии. М., 2006. 750 с.

13. Иванов С.Н. Технология бумаги. М., 2006. 696 с. 
Ivanov D.A. ${ }^{*}$ Ivanov K.A., Rudenko A.P., Alashkevich Iu.D. ON THE APPLICATION OF THE DEVICE SHAPED FORM WITH THE ROTOR HELICOIDAL TYPE FOR RECEPTION OF SANITARY PAPER

Siberian State Technological University, Mira ave., 82, Krasnoyarsk, 660049 (Russia),

e-mail: ivanov.sibstu@yandex.ru

The paper presents the research results of practical application of mixing apparatus of profiled form with the rotor helical type based on the definition of physico-mechanical and hydrophilic properties of tissue paper, providing the performance of sanitary-hygienic products.

The obtained results showed that the application of the mixing apparatus of profiled form with the rotor helical type for preparing the compositions of the paper pulp ensures the creation of a particular hydrodynamic environment in the working cavity of the device, allowing to minimize the possibility of stagnant zones both static and dynamic type and to reduce hydraulic losses along the trajectory of the fluid flow. This, in turn, leads to the maximum increase in the degree of circulation and uniform distribution of concentrations of fibrous suspensions for the preparation of the composition in paper pulp, providing the required physico-mechanical and hydrophilic properties of paper for sanitary purposes at a relatively low cost unit of electricity.

Keywords: the machine profiled shape, capillary absorption, breaking force, the rotor, tissue paper.

\section{References}

1. Bondarenko A. Tselliuloza. Bumaga. Karton, 2011, no. 7, pp. 22-24. (in Russ.).

2. Rudenko A.P., Eremenko V.V. Submitted to VINITI 12.05.03, №900-B2003, 2003, 16 p. (in Russ.).

3. Ivanov D.A., Ivanov K.A., Rudenko A.P. Molodye uchenye v reshenii aktual'nykh problem nauki: sb. st. Vseros. nauch.-prakt. konf. [Young scientists in solving actual problems of science: Proceedings of Scientific-Practical Conference]. Krasnoyarsk, 2010, vol. II, pp. 76-78. (in Russ.).

4. Ivanov D.A., Ivanov K.A., Rudenko A.P. Nauka i sovremennost' - 2011: sb. materialov IX Mezhdunar. nauch.-prakt. konf. [Science and modernity - 2011: Proceedings of the IX International scientific-practical conference]. Novosibirsk, 2011, part 2, pp. 29-32. (in Russ.).

5. Ivanov D.A., Ivanov K.A., Rudenko A.P. Khimiia rastitel'nogo syr'ia, 2013, no. 4, pp. 237-242. (in Russ.).

6. GOST R 52354-2005. Izdeliia iz bumagi bytovogo i sanitarno-gigienicheskogo naznacheniia. Obshchie tekhnicheskie usloviia. [State Standard P 52354-2005. Paper products and household and sanitary purposes. General specifications]. Moscow, 2005, 15 p. (in Russ.).

7. TR №024-43508418-2008. Bumaga - osnova dlia izdelii bytovogo i sanitarno-gigienicheskogo naznacheniia. OAO Sias'skii tselliulozno-bumazhnyi kombinat. [Technical Regulations №024-43508418-2008. Paper - basis for products for household and sanitary purposes. Syassky of Pulp and Paper Mill]. 2008,. 41 p. (in Russ.).

8. TR №006-43508418-2010. Bumaga - osnova dlia izdelii bytovogo i sanitarno-gigienicheskogo naznacheniia. OAO Sias'skii tselliulozno-bumazhnyi kombinat. [Technical Regulations №006-43508418-2010. Paper - basis for products for household and sanitary purposes. Syassky of Pulp and Paper Mill]. 2010, 43 p. (in Russ.).

9. Smolin A.S. Sovremennye tekhnologii i oborudovanie v proizvodstve sanitarno-gigienicheskikh materialov i izdelii: sbornik trudov Mezhdunar. nauch.-prakt. konf. [Modern technologies and equipment for the production of sanitary materials and products: a collection of the works of the International scientific and practical conference]. St. Petersburg, 2011, pp. 60-61. (in Russ.).

10. TU 5437-029-43508418-2011. Bumaga - osnova dlia izdelii bytovogo i sanitarno-gigienicheskogo naznacheniia. OAO Sias'skii tselliulozno-bumazhnyi kombinat. [Specifications 5437-029-43508418-2011. Paper - basis for products for household and sanitary purposes. Syassky of Pulp and Paper Mill]. 2011, 10 p. (in Russ.).

11. Vasil'tsov Z.A., Ushakov V.G. Apparaty dlia peremeshivaniia zhidkikh sred. [Apparatus for mixing liquid media]. Leningrad, 1989, 271 p. (in Russ.).

12. Kasatkin A.G. Osnovnye protsessy i apparaty khimicheskoi tekhnologii. [Basic processes and apparatuses of chemical technology]. Moscow, 2006, 750 p. (in Russ.).

13. Ivanov S.N. Tekhnologiia bumagi. [Technology papers]. Moscow, 2006, 696 p. (in Russ.).

Received December 25, 2014

Revised November 3, 2015

\footnotetext{
* Corresponding author.
} 